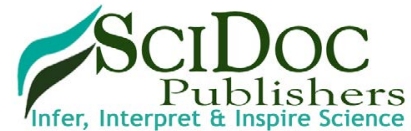

International Journal of Behavioral Research \& Psychology (IJBRP) ISSN 2332-3000

\title{
Microswitches-Based Programs for Post-Coma Patients with Acquired Brain Injuries
}

\author{
Editorial
}

Stasolla $\mathrm{F}^{1^{*}}$, Boccasini $\mathrm{A}^{2}$

${ }^{1}$ Department of Neurosciences, University of Bari, Italy.

${ }^{2}$ Lega del Filo d'Oro Research Center, Termini Imerese, Italy.

Post-coma persons with acquired brain injuries (ABI) may pose serious challenges to medical and/or rehabilitative centers. Beside traditional treatments, they may need specific interventions aimed at promoting their independence and resort their functioning accordingly. One way to profitably pursue this goal is the use of microswitches-based programs (MBP) [1]. Thus, within a MBP a person with multiple disabilities will be able to enhance his/her self-determination by autonomously access to preferred stimuli through the exhibition of small behavioral responses already available in his/her repertoire [2]. That is, based upon learning principles (i.e. causal association between a behavioral response and an environmental consequence), one may design different solutions, depending upon patients recovery perspectives [3].

For people in a vegetative state (i.e. vigilance without consciousness) one may envisage a MBP finalized at improving a minimal behavioral response recorded through a suitable microswitch for the independent access to brief periods of positive stimulation. For instance, a single eye blinking (i.e. behavioral response) may be detected by an optic sensor fixed on a eyeglass frame (i.e. microswitch), which will turn on favorite stimulation (e.g. 5-10 seconds of familiar voices) contingently to its activation, during intervention phases [4]. That is, subsequently to a baseline where the technology is available but inactive (i.e. no environmental consequences will be provided contingently to the exhibition of the behavioral response and microswitch activation), contingent intervention phases sessions will be carried out as to consolidate the learning process [5]. Once the performance is increased through a reversal design (i.e. double baseline-contingent intervention sequence), one may introduce a non-contingent intervention (i.e. control) phase, as supplement of learning assessment [6]. Thus, during the non-contingent phase, positive stimulation is always available throughout sessions, irrespective of participant's responding [7]. Whenever the participant's responding will decrease since the stimulation is available at any time within sessions, one may argue that participant's clinical condition may be labeled and considered as minimally conscious state rather than vegetative state [8].
For individuals in a minimally conscious state, one may resort to more sophisticated MBP [9]. For example, one may apply a MBP combined to a vocal output communication aid (VOCA) as to ensure participants with the double opportunity of independently access to preferred stimuli and/or request for social contact with parents or caregivers. Eventually, patients may choose between both options [10]. Otherwise, cluster technology may be used for the dual objective of augmenting an adaptive responding and simultaneously reducing a challenge behavior (e.g. postural abnormalities) [11]. Furthermore, one may improve communication skills such as phone calls and/or special text messaging systems with distant and relevant partners [12]. Once both clinical conditions and empirical evidences are favorable for a diagnosis of emergence from a minimally conscious state, more complex programs may be planned.

For patients emerging/emerged from a minimally conscious state who have extensive motor disabilities, MBP combined to a computer may foster leisure skills, the communication of personal needs to one or more caregivers, the independent access to literacy process [13]. Usually, a computer home page displayed on a suitable monitor in front of the participant, provides different options automatically scanned according to a predefined time interval adapted to participant's capacities, through a double cue (i.e. visual and verbal instructions). To select a desired option, participants are requested to perform the behavioral response and consequently activate the microswitch, once the aforementioned option is encircled and announced by the system. Subsequently, a second page will be provided with various items included in the previous category (e.g. personal needs). Once again participants are requested to perform the response and activate the microswitch for the selection. Once the item has been selected, a confirmation question concerning the item's desirability by the participant may be posed. By positive confirming it (i.e. YES responding) the item will be directly available or with the caregiver's mediation. Additionally, for literacy process, a keyboard emulator with rows and letters automatically scanned will be provided in combination with a word processor. To write down a word, participants

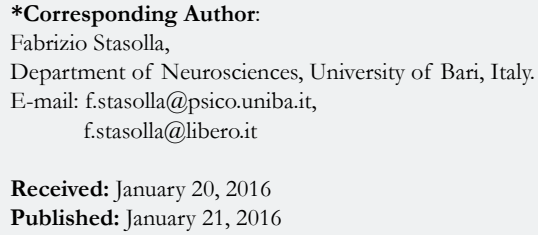

Copyright: Stasolla $\mathbf{F}^{\circ}$ 2016. This is an open-access article distributed under the terms of the Creative Commons Attribution License, which permits unrestricted use, distribution and reproduction in any medium, provided the original author and source are credited. 
will be requested to select first a row and subsequently a letter according to the above reported criterion. As sign of constructive engagement and quality of life, indices of positive participation may be further recorded [14].

In light of the above, future research perspectives within this framework should deal with the following topics: (a) wide extension of MBP to a large sample of ABI patients, (b) suitable provision of $\mathrm{AT}$ as individualized forms of educational and rehabilitative resources, and (c) social validation assessments involving parents, professionals and caregivers as external raters as to corroborate the clinical validity of such interventions [15].

\section{References}

[1]. Lancioni GE, Singh NN, O'Reilly MF, Sigafoos J, Buonocunto F, et al. (2011) Enabling persons with acquired brain injury and multiple disabilities to choose among environmental stimuli and request their repetition via a technology-assisted program. J Dev Phys Disabil 23(3): 173-182.

[2]. Lancioni GE, Bosco A, Belardinelli MO, Singh NN, O'Reilly MF, et al. (2010) An overview of intervention options for promoting adaptive behavior of persons with acquired brain injury and minimally conscious state. Res Dev Disabil 31(6): 1121-1134

[3]. Lancioni GE, Singh NN, O'Reilly MF, Sigafoos J, Belardinelli MO, et al. (2012) Promoting adaptive behavior in persons with acquired brain injury, extensive motor and communication disabilities, and consciousness disorders. Res Dev Disabil 33(6): 1964-1974.

[4]. Lancioni GE, Singh NN, O'Reilly MF, Green VA, Buonocunto F, et al. (2014) Microswitch-aided programs with contingent stimulation versus general stimulation programs for post-coma persons with multiple disabilities. Dev Neurorehabil 17(4): 251-258.

[5]. Lancioni GE, Bosco A, Belardinelli MO, Singh NN, O'Reilly MF, et al. (2014) Assessing learning as a possible sign of consciousness in post-coma persons with minimal responsiveness. Front Human Neurosci 8: 25.

[6]. Bosco A, Lancioni GE, Belardinelli MO, Singh NN, O'Reilly MF, et al.
(2009) Learning as a possible sign of non-reflective consciousness in persons with a diagnosis of vegetative state and pervasive motor impairment. Cogn Process 10(4): 355-359.

[7]. Lancioni G, Singh N, O'Reilly M, Olivetti M, De Tommaso M, et al. (2011) A learning assessment procedure as a test supplement for monitoring progress with two post-coma persons with a diagnosis of vegetative state. Dev Neurorehabil 14(6): 358-365.

[8]. Lancioni GE, Belardinelli MO, Chiapparino C, Angelillo MT, Stasolla F, et al. (2008) Learning in post-coma persons with profound multiple disabilities: Two case evaluations. J Dev Phys Disabil 20: 209-216.

[9]. Lancioni GE, Singh NN, O'Reilly MF, Sigafoos J, Boccasini A, et al. (2014) Microswitch-aided programs for a woman with Rett syndrome and a boy with extensive neuro-motor and intellectual disabilities. J Dev Phys Disabil 26(2): 135-143.

[10]. Lancioni GE, Belardinelli MO, Stasolla F, Singh NN, O'Reilly MF, et al. (2008) Promoting engagement, requests and choice by a man with postcoma pervasive motor impairment and minimally conscious state through a technology-based program. J Dev Phys Disabil 20(4): 379-388.

[11]. Lancioni G, O'Reilly M, Singh N, D'Amico F, Ricci I, et al. (2011) Microswitch-cluster technology to enhance adaptive engagement and head upright by a post-coma man with multiple disabilities. Dev Neurorehabil 14(1): 6064.

[12]. Lancioni GE, Singh NN, O'Reilly MF, Sigafoos J, Buonocunto F, et al. (2014) Occupation and communication programs for post-coma persons with or without consciousness disorders who show extensive motor impairment and lack of speech. Res Dev Disabil 35(5): 1110-1118.

[13]. De Pace C, Stasolla F (2014) Promoting environmental control, social interaction, and leisure/Academy engagement among people with severe/Profound multiple disabilities through assistive technology. In: Assistive Technologies and Computer Access for Motor Disabilities. 285.

[14]. Stasolla F, Caffò AO, Damiani R, Perilli V, Di Leone A, et al. (2015) Assistive technology-based programs to promote communication and leisure activities by three children emerged from a minimal conscious state. Cogn Process 16(1): 69-78.

[15]. Stasolla F, De Pace C (2014) Assistive technology to promote leisure and constructive engagement by two boys emerged from a minimal conscious state. Neuro Rehabilitation 35(2): 253-259. 